\title{
Preliminary Assessment of Cetacean Incidental Mortality in Artisanal Fisheries in Anakao, Southwestern Region of Madagascar
}

\author{
Yvette Razafindrakoto ${ }^{1}$, Norbert Andrianarivelo ${ }^{1}$, Salvatore Cerchio ${ }^{2}$, Irène Rasoamananto ${ }^{3}$, \\ Howard Rosenbaum ${ }^{2}$ \\ ${ }^{I}$ Madagascar Country Program, Wildlife Conservation Society BP 8500, 101 Antananarivo, Madagascar; \\ ${ }^{2}$ Cetacean Conservation and Research Program, Wildlife Conservation Society 2300 Southern Blvd, Bronx, NY \\ 10460-1099, USA; ${ }^{3}$ Institut Halieutique et des Sciences Marines, BP 141, 601 Toliara, Madagascar; ${ }^{4}$ Wildife \\ Conservation Society, Ocean Giants Program, 2300 Southern Blvd., Bronx, New York 10460, USA
}

Keywords: By-catch, artisanal fisheries, southwestern region, Madagascar, cetacean species

\begin{abstract}
Cetacean by-catch in artisanal fisheries in the southwestern region of Madagascar was previously documented through surveys conducted in this region. To build on initial findings, a research project was conducted to further evaluate by-catch in this region. Interview surveys were conducted between October 2005 and January 2006 in four seaside villages to gather information on cetacean by-catch in artisanal fisheries. A total of 111 interviews were analyzed, resulting in an estimate in 56 by-catch events in the four villages between 2000 and 2005. These events involved in an estimate of 79 animals entangled in fishing gear, which we believe is an underestimate. Three dolphin species and humpback whales were reported accidentally caught in fishing gear meant to catch sharks. Dolphins were mostly reported as to be entangled in gillnets; conversely longlines were only described to incidentally catch humpback whales. Bottlenose and spinner dolphins were respectively $48.10 \%$ and $31.64 \%$ of total cetacean by-catch between 2000 and 2005. Improved fisheries management and effective cetacean population management are needed to mitigate threats to cetaceans from artisanal fisheries in the southwestern region.
\end{abstract}

\section{INTRODUCTION}

The southwestern region of Madagascar is home to the spectacular coral reef formation, the Great Reef of Toliara (Battistini 1972). This ecosystem supports diverse marine resources and endangered species that contribute to the principal source of livelihood of the coastal communities. Previous reports showed that $75 \%$ of the pirogues (traditional canoes) in Madagascar's waters were used along the west coast (ICRI 1996). Fishermen along the southwestern coast mainly practice traditional and artisanal fishing techniques. These types of fisheries target a full range of exploitable resources in both shallow and pelagic waters. Deployment of largemeshed nets, targeting shark, turtles and fish, has resulted in incidental mortality of dolphins and whales in the western areas of Madagascar.

Many marine mammal species interact with fishing activities (Northridge \& Hofman 1999; Hucke-Gaete et al. 2004; Brotons et al. 2008; Sigler et al. 2008). These associations will result in accidental capture, which has been documented at various levels and at various frequencies worldwide (Perrin 1969; Lear \& Christenen 1975; Northridge 1991; Ashford et al. 1996; Amir et al. 
2002; Bordino \& Albareda 2004; Hucke-Gaete et al. 2004; Johnson et al. 2005). Incidental takes or by-catch can have serious impacts on cetacean populations (Crespo et al. 1997; Stacey et al. 1997; WWF 2004). The Cetacean Conservation and Research Program (CCRP) of The Wildlife Conservation Society initiated surveys to assess the extent of direct hunting and by-catch of small cetaceans. Surveys were conducted in Mahajanga (northwestern coast of Madagascar) between 1997 and 1998 and along the southwestern coast in 1999. These surveys indicated that Indo-Pacific humpback (Sousa chinensis), bottlenose (Tursiops $s p$ ) and Fraser's dolphins (Lagenodelphis hosei) were indirectly caught in fishing gear in these areas (CCRP unpublished data; Andrianarivelo 2001; Andrianarivelo et al., in preparation). Another short expedition held in 2004 revealed that small and large bodied cetacean species (e.g., a humpback whale calf, Megaptera novaeangliae) were also incidentally caught in nets in the southwestern region (Razafindrakoto et al. 2004). Although cetacean by-catch was reported to occur in this region, accurate information on its extent is still lacking.

During a workshop to design the National 20042007 Fishery and Aquaculture Plan, by-catch was identified as an important threat to many cetacean, sirenian and turtle species in Madagascar's waters. The report that followed this workshop documented the dearth of accurate information on by-catch in any fishery in Madagascar and recommended research and monitoring programs to enhance the protection of these species and other marine resources (Cooke 2004). Given the lack of accurate scientific information of by-catch in the southwestern region of Madagascar, we initiated research in collaboration with local fishermen to assess the degree of incidental capture of dolphins and whales between 2000 and 2005 and present our findings in this paper.

\section{MATERIALS AND METHODS}

\section{Description of the study site}

The study sites are located in the southwestern region of Madagascar (Fig. 1) between the latitudes $23^{\circ} 55^{\prime} \mathrm{S}$ and $23^{\circ} 32^{\prime} \mathrm{S}$. The survey area extends along approximately $60 \mathrm{~km}$ of coastline. Four main fishing villages were included in the study: Soalara $\left(23^{\circ} 35.6^{\prime} \mathrm{S}, 43^{\circ} 42.3^{\prime} \mathrm{E}\right)$, Anakao

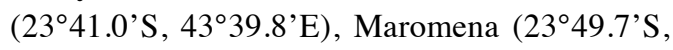

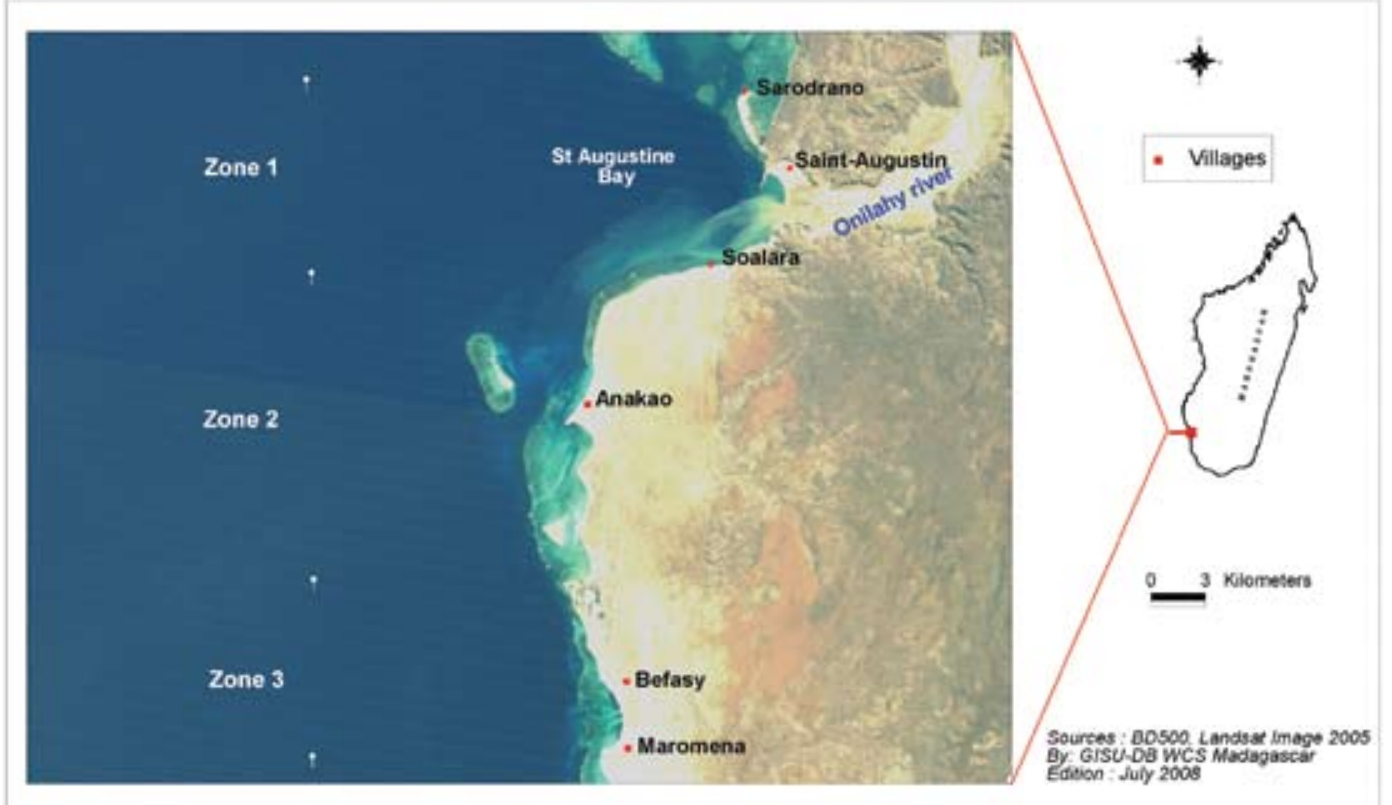

Fig. 1. Location of the four villages along the study area 
$\left.43^{\circ} 39.8^{\prime} \mathrm{E}\right)$ and Befasy $\left(23^{\circ} 48.3^{\prime} \mathrm{S}, 43^{\circ} 39.5^{\prime} \mathrm{E}\right)$. The study site was divided into three zones: Zone 1 includes Soalara village and stretched between the latitudes $23^{\circ} 32^{\prime} \mathrm{S}$ to $23^{\circ} 36^{\prime} \mathrm{S}$; Zone 2 between the latitudes $23^{\circ} 36^{\prime} \mathrm{S}$ to $23^{\circ} 44^{\prime} \mathrm{S}$ includes Anakao village; the two last villages Befasy and Maromena form Zone 3 between the latitudes $23^{\circ} 44^{\prime} \mathrm{S}$ to $23^{\circ} 49^{\prime} \mathrm{S}$. These villages belong to three distinct administrative districts and the delimitation was set according to this administrative zoning and also to facilitate monitoring given the extent of the survey area. The preliminary assessment of dolphin hunting by Andrianarivelo (2001) confirmed the importance of hunting in the southwestern region and as well the occurrence of bycatch in the artisanal fisheries. These four villages were then selected to collect information on incidental takes of marine mammals in the southwestern region. St Augustine Bay, north of Anakao, breaks up the Toliara reef system that shelters the shallow lagoons off these villages. The fringing reefs extend between 1.25 and $5.77 \mathrm{~km}$ off the coast. According to the 2005 population census by the local administrative authority, 8474 people inhabit the four littoral villages with 3597 (42\%) of these inhabitants reporting to be fishermen.

\section{Interview-based by-catch assessment}

Previous experience in the region and the sensitivity of the issue of dolphin hunting dictated the approach we used to monitor bycatch. Dolphin hunting has historically been a common activity of fishermen in the three zones. In response to this pressure, previous management effort worked to develop local rules in 1999 to reduce dolphin hunting. Fishermen who hunt dolphins were mandated to pay a fine of 50,000 Fmg (US\$50 in 1999) (Andrianarivelo 2001). Many studies in the region have used interview methodologies for collecting information and feedback from these studies were given to the local communities (Walker et al. 1992; Andrianarivelo 2001, Bill \& Mermet 2002; Frontier Madagascar 2003, McVean et al. 2005; McVean et al. 2006). Therefore, in order to avoid over-burdening fishermen with interviews a new approach for assessing by-catch was proposed by the CCRP. Although direct observation from fishing vessels provides accurate information on by-catch, we did not attempt to place observers on fishermen's vessels in order to maintain villagers' confidence in our project. Fishermen were initially asked to report cetacean entanglement in their nets via datasheets (Secchi et al. 2004). However, fishermen remained unwilling to self-report incidental catch due to the sensitivity surrounding former dolphin hunting in the area. As a result, fishermen were generally uncooperative in reporting their captures of marine mammals on datasheets. Therefore, despite our previous concerns about conducting interviews in this region, we abandoned this self-reporting methodology (Secchi et al. 2004) and proceeded with interviews for collecting by-catch data in the four villages. The respondents were asked to report by-catch events within the period of 2000 and 2005. A single page questionnaire was prepared to collate data related to by-catch in the four villages (Appendix 1). Specific questions related to cetacean by-catch, fishing zones, dolphin sighting, fishing information (net characteristics, fishermen information, and fishing zone) in the southwestern region were used to collate information from fishermen. Attempts were made to quantify the number of fishing gears used by fishermen, but some of them felt offended when asked this question and therefore, only the length, depth and mesh sizes of the nets were requested. The common names of cetacean species were recorded as reported by the fishermen. The corresponding scientific names were obtained during boat based surveys which were conducted consecutively with the interview sessions to examine cetacean diversity. Due to the sensitive nature of the question the interviewer estimated the respondent's age. The interview surveys were conducted by two Malagasy researchers from CCRP and one Malagasy student from the Institute for Fisheries Management and Marine Sciences in Toliara (Institut Halieutique et des Sciences Marines - (IH.SM) between October 2005 and January 2006 in the four littoral villages. In addition, two fishermen were hired to record by-catch events in Zones 2 and 3, respectively, between January and May 2006. The sampling method used consisted of setting criteria that helped to identify and to select the respondents. Since cetacean species were reported to interact with longlines and driftnets in the southwestern areas (Andrianarivelo 2001; Andrianarivelo pers 
comm), fishermen using these types of fishing gears should have knowledge or insight of by-catch in the areas. One fisherman in each village was employed as an interpreter/facilitator for the interviews and helped the team to identify the persons who were considered trustworthy and likely to respond readily to the survey.

The situation described at the beginning of the methodology section has often conditioned the enthusiasm of the fishermen to respond. An approach was developed to aid the interviewees in sharing information on by-catch events and for the research team to gauge its authenticity. The local guide was able to inspire confidence in the respondents and also was able to gauge the veracity of responses during interviews. The latter was semi-structured to enhance respondent comfort when sharing by-catch data. To illustrate this methodology, an overview of by-catch issues in other places around Madagascar and the world was provided. This was done before any questions related to by-catch were asked in the villages. This approach assured the interviewees that by-catch is not specific to the region, but occurs and is being evaluated on regional and global levels. The semi-structured, informal approach was effective at making the fishermen more comfortable when sharing their experience and knowledge on the subject. Each interview lasted approximately 15 minutes and the three members of the research team assessed the consistency of the answers. Different criteria, such as the behavior of the interviewees when responding to questions, our own knowledge of the species biology and the suitability of the responses were used to assess the reliability of the answers. Each answer was assigned to a rating of: 1 $=$ reliable, $2=$ useful, or $3=$ unreliable. Each team member independently recorded their evaluation of the fishermen's reliability. After the interview session, the team compared evaluations and, where individual ratings differed, agreed on the ratings that should be attributed to each interview.

Considering the sensitivity of dolphin killing in the villages, any attempt to quantify by-catch per units, e.g. household, type of nets, type of vessels etc, was not conducted during the interview session. News of dolphin catches spread rapidly throughout the villages and respondents may report by-catch events seen in another place.
Therefore, each response from a fisherman was considered as a bycatch event for a given village. All responses were entered into a database for evaluation. Many answers from fishermen in the four villages appeared to relate to a same single event in a given zone. Answers were considered to be duplicates when the information related to the period (year), the place where it occurred, and the number of animals involved was the same. When such duplications were suspected, only one of the answers was retained and included in the data analysis.

\section{RESULTS}

\section{Sampling effort}

A total of 282 people participated in the interviews, representing $8 \%$ of the fishermen in the four villages (Table 1). A total of 204 interview answers on by-catch were recorded from the fishermen in the four villages, 93 of which (46\%) appeared to be duplicated information. Therefore, the by-catch data between 2000 and 2005 were analyzed from 111 unique responses. According to our rating of the answers, $67 \%$ were reliable (Code 1), $31 \%$ were acceptable (Code 2) and $3 \%$ were not reliable (Code 3 ). The answers ranked in code 3 were excluded from the analysis.

\section{Description of the artisanal fisheries}

Fishing constitutes the principal livelihood of the communities in the four coastal villages. Overall, invertebrates, reef fishes, small and large pelagic fishes including shark and turtles are targeted in the waters of the three zones. Shark fishermen tend to fish in an area approximately $2-6 \mathrm{~km}$ off the

Table 1. Partitioning of fishermen interviewed in each fishing zone: the numbers in italics are the interviewees in each zone; the numbers in normal font are fishermen interviewed in one zone but also indicated that they moved in different zones to fish

\begin{tabular}{lrccc} 
Villages & Anakao & Soalara & Maromena & Befasy \\
\hline Zone 1 & 111 & 7 & & \\
Zone 2 & 97 & 51 & 9 & 7 \\
Zone 3 & 1 & 7 & 63 & 57 \\
\hline
\end{tabular}


fringing reefs. The length of the study site is about $60 \mathrm{~km}$ along the shore. Consequently, the area of the fishing zone took in the study includes about $240 \mathrm{~km}^{2}$. The abundance of marine resources in the waters of one zone may determine the movement of fishermen between villages to fish (Table 1).

Based on FAO classification (IWC 2004), four types of fishing gear are used by fishermen in the four villages: 1- grappling and wounding, 2- line and hook, 3- gillnet and entangling nets, 4-seines. Driftnets (GND) and set long lines (SLL) are commonly used to catch sharks in the southwestern region and have been shown to entangle cetacean species. GND and SLL are baited with cephalopods or tuna. Small- to large-meshed GND, ranging in size from $2 \mathrm{~cm}$ to $60 \mathrm{~cm}$, are deployed in the waters of the three zones. The common GND type known locally as jarifa had a mesh size between $30 \mathrm{~cm}$ and $35 \mathrm{~cm}$. In recent years, they introduced another GND type, known locally as "GTZ"/“ZZ" whose mesh sizes ranges between $14 \mathrm{~cm}$ and $16 \mathrm{~cm}$. Both types of GND nets are made with synthetic nylon twine. In addition, fishermen also make small meshed nets ( $2-4 \mathrm{~cm}$ mesh sizes), made with used nets from industrial fisheries, remains of car tires and twine. Gillnets range between $50 \mathrm{~m}$ and $500 \mathrm{~m}$ in length and between $4 \mathrm{~m}$ and $6 \mathrm{~m}$ in depth.

Since 2000, fishermen have stopped using the large meshed nets (jarifa) and have replaced them with set long lines (SLL). SLL are composed of three parts: the buoy line, float lines and hook lines. The buoy line connects the anchor to the surface system. The hook lines are attached to a buoy at regular intervals. SLLs range between 100 $\mathrm{m}$ and $400 \mathrm{~m}$ in length and are usually deployed at a depth of $4 \mathrm{~m}$. At present, SLLs are commonly used to catch sharks in the four villages. However, "GTZ"/“ZZ" nets are only used by a few wealthy fishermen and mostly by fishermen associations because to their high price.

\section{Reported by-catch events in the four villages}

From the interviews, four cetacean species were reported as by-catch in the four villages, Indo-Pacific humpback dolphins (Sousa chinensis), bottlenose dolphins (Tursiops spp.), spinner dolphins (Stenella longirostris) and also several takes of humpback whales (Megaptera novaeangliae). Bottlenose dolphins and spinner dolphins appeared to represent the largest proportions of the animals incidentally caught in the four villages, being respectively $48.10 \%$ and $31.64 \%$ of total estimated cetacean bycatch between 2000 and 2005 (Fig 2). Bottlenose dolphins were also the common species by-caught in the three zones (Fig.3).

Responses indicate that a total of 79 animals were entangled in fishing gear throughout the entire study site during the period of 2000 to 2005 . The observers reported no incidental mortalities during the period of January to May 2006. However during the same period, the observer in Maromena and Befasy (Zone 3) reported the hunting of two spinner dolphins and three blackfish whose Malagasy common name, "fefidoha", describes the pronounced bulbous form of its forehead. Respondents reported 36 events of by-catch in large- and medium-meshed gillnet and 20 in long lines between 2000 and 2005. The number of cetaceans incidentally caught in SLLs was low compared to those captured in GNDs (Table 2). However, the SLLs were the only type of fishing gear that entangled humpback whales during the period of study. The whales were first trapped by the float lines and then are further entangled by the buoy lines when the animal attempts to escape from float lines. Dolphin species were mostly entangled in the GND nets. The proportion of dolphins incidentally caught was similar (43\%) between the $30-40 \mathrm{~cm}$ meshed GND (or jarifa), and the new $14-20 \mathrm{~cm}$

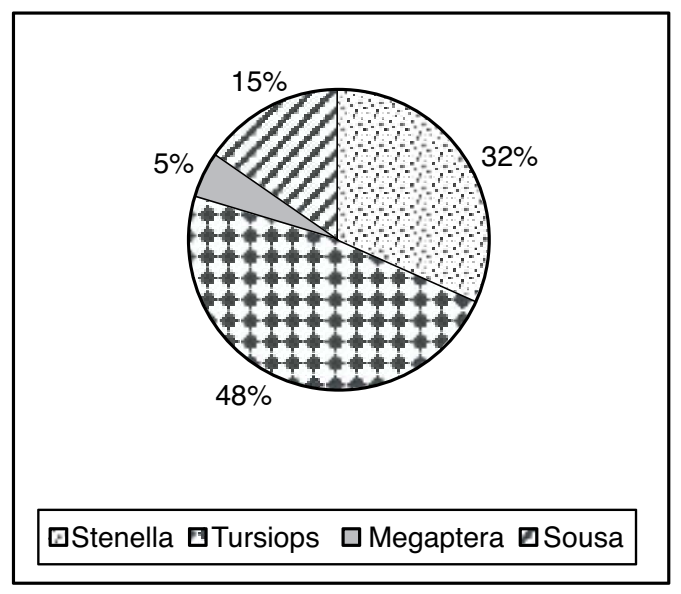

Fig. 2. Percentage of cetacean genera caught incidentally between 2000 and 2005 


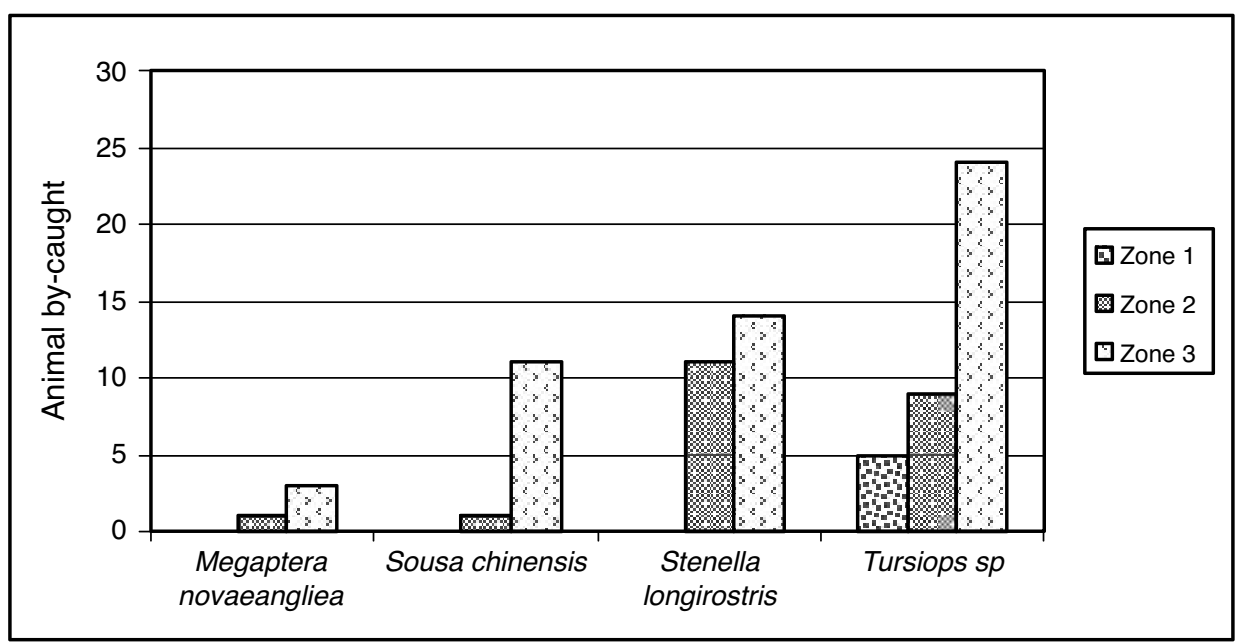

Fig. 3. Cetacean species caught in each zone

Table 2. The number of animals incidentally caught per fishing gear during the period of 2000-2005

\begin{tabular}{lcc}
\hline Species & Catches/GND & Catches/SLL \\
\hline Bottlenose dolphin & $39.24 \%(31)$ & $8.86 \%(7)$ \\
Spinner dolphin & $18.99 \%(15)$ & $12.66 \%(10)$ \\
Humpback dolphin & $15.19 \%(12)$ & 0 \\
Humpback whale & 0 & $5.06 \%(4)$ \\
\hline
\end{tabular}

meshed GND, (or “GTZ/ZZ”) (Fig.4). In addition, personal observation of scars on individual dolphins seems to suggest dolphin entanglements in nets (Fig. 5).

\section{DISCUSSION AND CONCLUSION}

Marine resources are the principal source of income of the communities in the southwest of Madagascar. Different types of fishing gear have been used to collect marine resources. The information collected through the interviews showed that cetacean coastal species have been interacting with artisanal fisheries. Gillnets and longlines targeting sharks were reported mostly to incidentally catch dolphins and whales in the three zones. The large meshedGND (jarifa) commonly entangled bottlenose, spinner and humpback dolphins and floating and buoy lines of SLL have also entangled humpback whales and dolphins in the southwestern region. Longline are reported to be a potential risk for entanglement to humpback whales and North
Atlantic right whales in the western North Atlantic (Johnson et al.2005). Incidence of dolphin by-catch with the large meshed-GND was also reported to be high in the western region of Madagascar (CCRP unpublished data). The results showed that the number of dolphins incidentally caught with the large and new medium meshed gillnets was proportionally similar. The use of fish and cephalopods as bait may also attract dolphins to both net types. In general, a $100 \mathrm{~m}$ length of GND is baited with two - five kilograms of fish (Rakotondrasoa 2005). Gillnets have been reported to entangle small and large marine mammal species in artisanal and also commercial fisheries in many parts of the world (Julian and Beeson 1998; Baird et al. 2002; Amir et al. 2002; Bordino \& Albareda 2004; Broton et al. 2008). The introduction of the costly new gillnets may not change the by-catch situation in the three zones and few fishermen can afford them.

Bottlenose, spinner and Indo-Pacific humpback dolphins were the common species reported as by-catch in artisanal fisheries in the southwestern region. The information from fishermen related to the species incidentally caught and/or observed in the areas matched with the sightings made by CCRP team from boat based surveys off the waters of the study sites (Andrianarivelo 2001; CCRP unpublished data). However, it is interesting that spinner dolphins were not reported incidentally caught in the previous survey (Andrianarivelo 


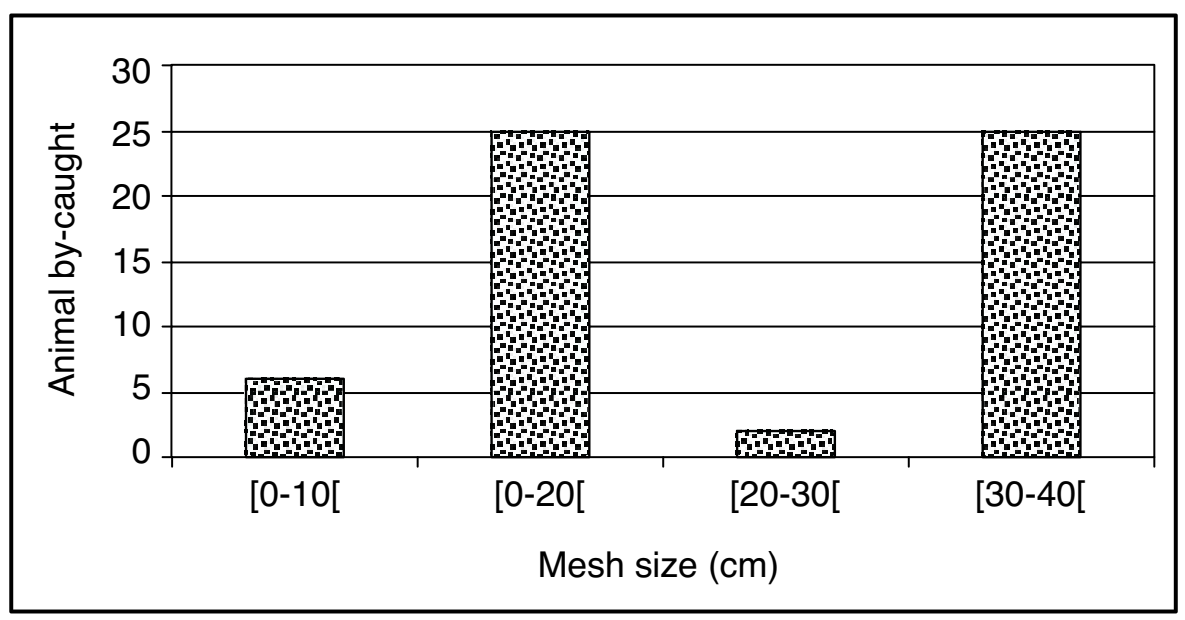

Fig. 4. Dolphins caught by types of gillnets between 2000 and 2005
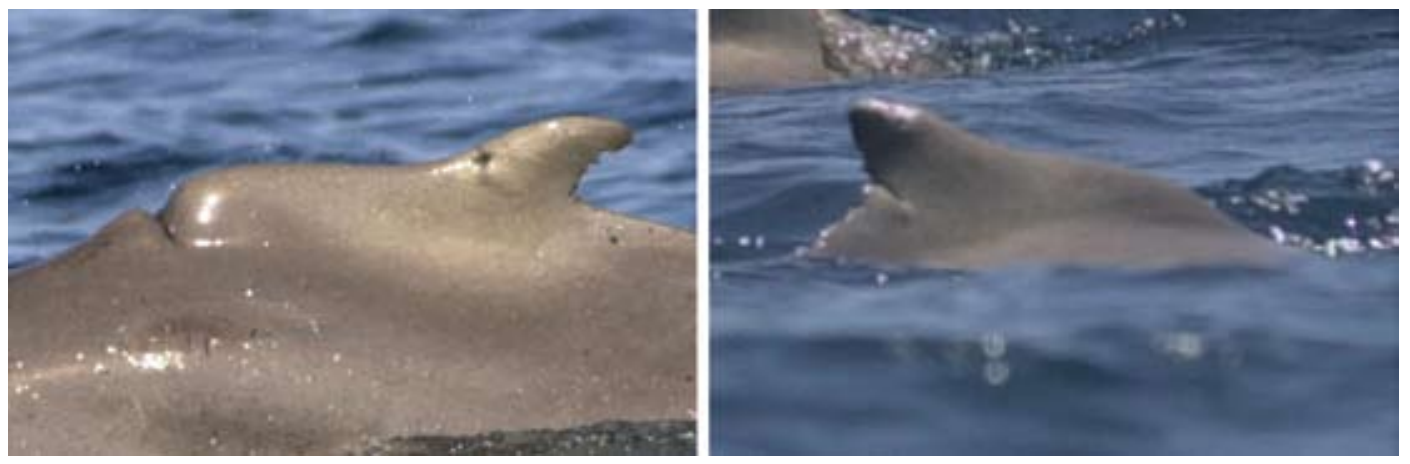

Fig. 5. Scars on humpback dolphins' bodies possibly due to entanglement events

2001) though Fraser's dolphins were detected as by-catch. The similarity in the striped pattern of the coloration presented by both species may confound their identification and consequently the names given by the fishermen. A hand drawn marine mammal poster produced by WWF was shown to fishermen to identify the species in the villages during the previous survey (Andrianarivelo 2001). This type of illustrated cetacean guide mostly helped to inform on the common species encountered by the fishermen.

The information that we collected through the interview likely represents an underestimation of the true by-catch in the three zones. This result may be related to the choice of the technique used to collect data. Interview techniques have often been qualified as unreliable for quantitatively assessing by-catch (UNEP/CMS 2005). Answers from fishermen on the captures may not be sufficiently specific to accurately assess the true extent of bycatch. The responses may be biased by limitations of the fishermen's recollection, the fear of possible reprimand to report dolphins' mortalities because of the local rule set in the villages and, possibly of greatest concern, is that fishermen may not want to be truthful with their responses. This latter case was apparent when 150 - 200 spinner dolphins were directly killed in zone 2 during the period when we conducted interviews in Anakao (CCRP unpublished data). None of the fishermen revealed this event during the interview process and it was discovered independently by our team members. The by-catch estimates may not reflect the magnitude or extent of incidental mortalities issues in the southwestern region. However, bycatch was considered as threat to cetaceans in this region. According to the fishermen who attended a 2007 workshop held in Anakao the creation of an 
incentive program for releasing animals entangled in nets was suggested to help mitigate dolphin by-catch (WCS \& Madagascar National Parks, ex-ANGAP unpublished data). This workshop was prepared in the framework of a development of an ecotourism project in the southwestern region. With respect to the observations described here, the development of alternative livelihoods through the introduction of conservation oriented ecotourism may help promote more sustainable use of the marine resources and improved conservation practices in the southwestern region. Therefore, improved fisheries management should be one of the authorities' priorities to enhance the sustainability of marine resources in the region.

Acknowledgments - We appreciate the dedication given by all members of the research team, the boat driver and his assistant, and the IH.SM students who contributed to the collection of data. We thank the logistic support from IH.SM in this work. We are also grateful to the mayors of Anakao and Soalara who allowed us to conduct the research work in the four villages Soalara, Anakao, Maromena and Befasy. This project would not have been possible without the efforts and participation of the fishermen in the four villages. Funding for this research was provided by the WWF/By-Catch fund facilitated through the International Whaling Commission. Thanks to Georgina Cullman for her valuable comments that helped to improve the paper.

\section{REFERENCES}

Amir, O.A., Berggren, P. and Jiddawi, N. S. 2002. The incidental catch of dolphins in gillnet fisheries in Zanzibar, Tanzania. Western Indian Ocean Journal of Marine Science 1: 155-162.

Andrianarivelo,N. 2001.Inventaire et essai d'évaluation de l'importance de la pêche aux dauphins d'Anakao, région sud - ouest de Madagascar. Mémoire de DEA. Institut Halieutiques et des Sciences Marines, Université de Toliara. 61 pp.

Ashford, J. R., Rubilar, P. S. and Martin, A. R. 1996. Interactions between cetaceans and longline fishery operations around South Georgia. Mar. Mammal Sci. 12: 452- 457.

Baird, R. W., Stacey, P. J., Duffus, D.A. and Langelier K. M. 2002. An evaluation of gray whale (Eschrichtius robustus) mortality incidental to fishing operations in British Columbia, Canada. J. Cetacean Res Manage 43: 289-296.

Battistini, R. 1972. Madagascar relief and main types of landscape. In Richard-Vindard and Battistini (Eds). Junk, The Hague. Biogeography and Ecology of Madagascar. p 1-25.

Bill, R. \& Mermet L. 2002. Integrated coastal management at the regional level: lessons from Toliara, Madagascar. Ocean \& Coastal Management 45: 41-58.

Bordino, P and Albareda, D. 2004. Incidental mortality of Fransiscana dolphin, Pontoporia blainvillei in coastal gillnet fisheries in northern Buenos Aires, Argentina. Paper SC/56/SM11 submitted to the Scientific Committee of the International Whaling Commission. 7 pp.

Brotons J. M., Grau, A. M. and Rendell, L. 2008. Estimating the impact of interactions between bottlenose dolphins and artisanal fisheries around Balearic Islands. Mar. Mammal Sci. 24: 112-127.

Cooke, A. 2004. Orientation, opportunités et actions environnementales pour le secteur pêche et aquaculture à Madagascar. In C. Andrianaivojaona, R. Rafidison, Z. Kasprzyk, M. Andriantsoa \& E. Ranaivoson (Eds). CITE Antananarivo Madagascar. Pêche et Aquaculture à Madagascar Plan Directeur 2004-2007 du secteur pêche et aquaculture. $161 \mathrm{pp}$.

Crespo, E. A., Pedraza, S. N., Dans, S. L., Alonso, M. K., Reyes, L. M., García N. A., Coscarella M. and Schaivini A. C. M. 1997. Direct and Indirect effects of the highseas fisheries on the marine mammal populations in the northern and central patagoniana coast. J. Northw. Atl. Fish. Sci 22: 189-207.

Frontier Madagascar. 2003. Fin -fish resource use: artisanal fisheries in Beheloka. In Woods-Ballard A. J., Chiaroni L. D. and Fanning, E. (Eds). Frontier Madagascar Environmental Research Report 11. Society for Environmental Exploration, UK and 1'Institut Halieutiques et des Sciences Marines. 16 pp.

Hucke-Gaete, R., Moreno, C. A., and Arata, J. 2004. Operational interactions of sperm whales and killer whales with the Patagonian toothfish industrial fishery off southern Chile. CCAMLR Science 11: 127-140.

ICRI. 1996. Atelier regional de 1'Océan Indien occidental. Seychelles 29 March - 2 April 1996. International Coral Reef Initiative. Unpublished Report. 4pp.

IWC. 2004. Report of the sub-committee on estimation of bycatch and other induced mortality. Report of the Scientific Committee of the IWC, 56 Annex I. 
Johnson, A., Salvador, G., Kenney, J. Robbins, J., Kraus, S. Landry, S. and Clapham, P. 2005. Fishing gear involved in entanglement of right and humpback whales. Mar. Mammal Sci. 21: 635-645.

Julian, F. and Beeson, M. 1998. Estimates of marine mammal, turtle and seabird mortality for two California gillnet fisheries: 1990-1995. Fish. Bull. 96: 271-284.

Lear, W. H. \& Christenen, O. 1975. By-catches of harbour porpoises (Phocoena phocoena) in salmon driftnets at West Greenland in 1972. Journal of Fisheries Research Board of Canada 32: 12231228.

McVean, A. R., Herrery G., Walker R. C. J., Ralisaona, B. L. R. and Fanning, E. 2005. La pêche traditionnelle de l'holothurie dans le sud-ouest de Madagascar: une étude de cas réalisée sur deux villages en 2002. Bull. de CPS 21: 15-18.

McVean, A. R., Walker, R. C. J. \& Fanning E. 2006. The traditional shark fisheries of the southwest Madagascar: A study in the Toliara region. Fisheries Research 82: 280-289.

Northridge, S. P. 1991. Driftnet fisheries and their impacts on non-target species: a world-wide review. FAO Fisheries Technical Paper No. 320. $115 \mathrm{pp}$.

Northrigde, S. P. and Hofman, R. J. 1999. Marine mammal-fishery interactions. In J. R. Twiss and R. R. Reeves (eds). Conservation and management of marine mammals. Smithsonian Institution Press. Washington, DC. p 99-119.

Perrin, W.F. 1969. Using porpoise to catch tuna. World Fishing 18: 42-45
Rakotondrasoa. M. J. 2005. Contribution à l'analyse de la filière requin. Unpublished Report of the Ministry of the Agriculture and Fisheries \& The Wildlife Conservation Society. 20 pp.

Razafindrakoto, Y.,Andrianarivelo, N. and Rosenbaum, H. C. 2004. Sightings, catches and other records of Indo-Pacific humpback dolphins in the coastal water of Madagascar. Aq. Mammal 30: 103-110.

Secchi, E.R., Kinas, P.G. \& Muelbart M. 2004. Incidental catches of fransiscana in coastal gillnet fisheries in the Fransiscana Management Area III: period 1999-2000. Lat. Am. J. Aquat. Mamm 3: $61-68$

Sigler, M. F., Lunsford, C. R. , Straley, J. M. and Liddle, J. B. 2008. Sperm whale depredation of sablefish longline gear in the northeast Pacific Ocean. Mar. Mammal Sci. 24: 16-27.

Stacey, P. J. Duffus, D. A., and Baird, R. W. 1997. A preliminary evaluation of incidental mortality of small cetaceans in coastal fisheries in British Columbia, Canada. Mar. Mammal Sci. 13: 321326.

UNEP/CMS. 2005. Report of the second workshop on the biology and conservation of small cetaceans and dugong of South-East Asia. UNEP/CMS Secretary, Bonn Germany. 161pp.

Walker R. C. J., Roberts, E. \& Fanning E. 1992. The trade of Marine turtles in the Toliara region, South West Madagascar. Marine Turtle Newsletter 106: 7-10

WWF. 2004. Cetacean by-catch and the IWC. WWF Gland Switzerland. 8pp. 


\section{APPENDIX 1}

Questionnaire for assessing by-catch in the four villages in the southwestern zone of Madagascar

\section{A. Information on the interviewees}

Identification number of the fisherman:

Estimation of the age:

Sex:

Village:

Date:

Start time:

Rating of the response:

1

End time:

$$
2
$$

B. Information on the fishing zone

Where do you go to fish:

\section{Information on the by-catch}

Has you heard occurrence of cetacean by-catch in fishing gears:

If yes, when (Year)?

What is the species?

What type of fishing gear does entangle cetaceans?

\section{Characteristics of the fishing gears}

Length (Net, Line):

Depth (Net, Line)

Mesh size:

Material used to make the nets:

\section{E. Cetacean sightings for the day}

Species observed: $\quad$ Estimation of animal number

Where?: 